SILVANA BOONE

[]

UMA BREVE HISTÓRIA DA

CURADORIA

- HANS ULRICH OBRIST - 


\section{UMA BREVE HISTÓRIA DA CURADORIA - HANS ULRICH OBRIST -}

Sempre que um livro sobre arte é publicado em português, num período de tempo relativamente curto em relação ao seu original, temos a confortável sensação de melhoria do mercado editorial e do interesse pela arte no Brasil. É muito bem recebida a edição de Uma breve história da curadoria, de Hans Ulrich Obrist, curador e crítico de arte suíço, originalmente publicado em 2008 e recém-lançado no Brasil.

O livro reúne uma série de entrevistas feitas com onze dos mais renomados curadores de arte, pioneiros na área, atuantes nos anos 1960/70 e que estiveram à frente de grandes exposições e de alguns dos principais museus e galerias do mundo. Em diálogos de caráter informal, as entrevistas obtidas entre 1995 e 2007 promovem uma valiosa discussão em torno do trabalho curatorial, dos processos e das exigências na organização de exposições, seus trânsitos burocráticos, políticos, as questões econômicas que norteiam as exibições e o papel do museu como um agente de aproximação entre a arte, o artista e o público.

$\mathrm{Na}$ apresentação de Nessia Leonzini, a partir da explicação do conceito que vem do latim curare, enquanto cuidar e conservar as obras de arte, surge logo o questionamento: quem é e o que faz um curador? Na introdução da entrevista de Harald Szeemann, obtemos a resposta: o curador, em suas diversas funções, é também diretor de museu/galeria, organizador de exposições, arquivista, conservador, negociador (de arte), assessor de imprensa, cúmplice de artista, enfim, múltiplos papéis que se (con)fundem em um só. Por sua vez, Christophe Cherix, no prefácio do livro, diz que o papel do curador também é o de crítico de arte; faz referência à história das exposições, às coleções e aos museus modernos criados no século $X X$; e com as exposições, surge a figura do curador, cuja responsabilidade ultrapassa as fronteiras do título.

As entrevistas de Werner Hofmann, Walter Zanini, Anne d'Harnoncourt e Lucy Lippard eram inéditas até a publicação original, em 2008. As demais haviam sido publicadas em diferentes revistas especializadas.
Os curadores entrevistados, em ordem de aparição no livro, são Walter Hopps, Pontus Hultén, Johannes Cladders, Jean Leering, Harald Szeemann, Franz Meyer, Seth Siegelaub,Werner Hofmann, o brasileiro Walter Zanini, Anne d'Harnoncourt e Lucy Lippard. Através das entrevistas,' o autor objetiva registrar os relatos de exposições e das primeiras curadorias, cuja documentação é escassa e durante muito tempo 
não foi investigada na essência da sua história. $\mathrm{Na}$ entrevista de cada curador, muitas lembranças ainda não contadas na história da arte.

Walter Hopps (1923-2005), curador americano, iniciou sua trajetória muito jovem, administrando uma pequena galeria e um negócio de jazz, simultaneamente, em Los Angeles. A entrevista questiona a recepção das exposições, a convivência com artistas, cita curadores importantes naquele contexto, bem como destaca a exposição inclusiva intitulada Thirty-six hours, em Washington, cujo objetivo era abrir um espaço alternativo para que o público levasse qualquer coisa para expor, uma proposta ousada, sem distinção entre artistas ou não artistas.

O curador sueco Pontus Hultén (1923-2006), responsável pelo Museu Moderno de Estocolmo, destaca a exposição de Marcel Duchamp realizada em 1960, o papel desse artista no contexto da arte e comenta sobre seu trabalho junto às galerias, suas exposições realizadas em Estocolmo e outras grandes cidades da Europa e nos Estados Unidos. Hultén, quando questionado sobre o museu, diz que é fundamental criar um público fiel. Entre as várias exposições realizadas pelo curador, Obrist dá importância maior às trocas artísticas: Paris - Nova York, Paris - Berlim, Paris - Moscou e Paris - Paris e ressalta o Centro Georges Pompidou como museu de arte adotado pelo público. $O$ entrevistado menciona alguns curadores com os quais mantinha um diálogo frequente, artistas que tiveram importância na sua trajetória, como Jean Tinguely e Niki de St. Phalle, e as exposições que marcaram sua carreira e que ainda são lembradas.

Johannes Cladders (1924), curador alemão, foi diretor do Museu Municipal Abteiberg, em Mönchengladbach, e o responsável pelo reconhecimento internacional de Joseph Beuys. A entrevista traz ao público os processos no início da sua carreira, com a primeira retrospectiva de Beuys, a invenção das caixas-catálogo, a reflexão sobre as relações entre arte e vida dentro do museu e como tornou o museu de uma cidade pequena em uma das maiores referências em arte e curadoria na Europa.

Jean Leering (1934-2005), curador holandês e arquiteto, iniciou sua carreira em 1958, com uma exposição sobre arquitetura autônoma. Teve a interdisciplinaridade como questão central da prática curatorial e, na entrevista, menciona suas referências como curadores, a situação social da década de 1970 na Europa e as exposições mais importantes. Ao final, questionado sobre a ideia de museu, ele mantém a interrogação feita por Obrist, desejando um futuro baseado nas tentativas de construção desse conceito e desenvolvidas por ele ao longo das suas décadas mais produtivas.

O curador suíço Harald Szeemann (1933-2005) dizia-se um organizador de exposições. Conhecido como diretor da Kunsthalle de Berna, por nove anos desde 1960, com cerca de doze exposições por ano, após 1969 tornou-se o curador independente de um método que chamou de "informação seletiva e/ou seleção informativa”. Apresenta a Obrist sua percepção sobre curadores, artistas diversos, 
novos museus, mas focaliza, em suas respostas, o caráter da informação e o conceito de arquivo como documento.

Franz Meyer (1919-2007), antecessor de Szeemann na Kunsthalle, ao contrário deste, não se considera um organizador de exposições. Em sua entrevista, destaca algumas de suas curadorias, como as das obras de Malevitch e Matisse, sua ida para o Museu da Basiléia, em 1962, sua relação com a arte moderna e contemporânea e a sua percepção em relação ao futuro do museu, o poder financeiro e as privatizações. Tinha um grande interesse pela relação entre o artista e a percepção do espectador em relação à obra.

O curador americano Seth Siegelaub (1942) inicia sua entrevista explicando a edição especial da revista Art Press, The context of art/The art of context, publicada em 1996, cujo objetivo foi reunir opiniões dos artistas (um total de setenta entrevistas) sobre o universo da arte desde 1960. Outras questões discorrem sobre a estrutura de museu, a relação entre artistas, galerias e colecionadores e os aspectos socioeconômicos da arte, mas, talvez, a questão principal seja a reflexão que faz sobre o papel do curador como um agente no processo de exposição, do tornar visível e fazer compreender o que está exposto.

Werner Hofmann (1928), diretor fundador do Museu do Século XX, emViena, de 1962 a 1969, e da Kunsthalle de Hamburgo, de 1969 a 1990, menciona seus estudos iniciais sobre história da arte e as primeiras exposições sobre Goethe, Chagall e Henry Moore, seu contato com René d'Harnoncourt, sua ida para os Estados Unidos e sua dedicação à arte do século $X X$ a partir da metade da década de 1950. Destaca sua transição de pesquisador a museólogo prático, as dificuldades e os sucessos junto ao Museu de Viena e, posteriormente, em Hamburgo.

Em entrevista concedida a Obrist, juntamente com Ivo Mesquita e Adriano Pedrosa, em 2003, o curadorWalter Zanini (1925), único brasileiro no livro, apresenta o início de sua carreira na Europa, como estudante de história da arte, e seu retorno ao Brasil, em 1962, como professor na Universidade de São Paulo. Dá ênfase aos anos em que foi diretor do Museu de Arte Contemporânea da USP e às primeiras exposições que organizou no MAC, destacando a exposição itinerante Meio século de arte nova, em 1966, com obras de artistas como Kandinsky, Leger, Boccioni e os brasileiros Di Cavalcanti, Anita Malfatti, lberê Camargo, entre outros. Destaca a relação entre museus e curadores da America Latina e a importância das relações próximas com os artistas. A entrevista ainda enfatiza a participação de Zanini como curador das Bienais de São Paulo, em 1981 e 1983, e as transformações ocorridas no seu formato a partir de então.

A curadora alemã Anne d'Harnoncourt (1924), especialista em Marcel Duchamp, ocupa parte da entrevista na referência ao pai, René d'Harnoncourt, que esteve à frente do MoMA-NY de 1949 a 1967, a ligação dele com os artistas e a aproximação dela 
com esses por meio do ofício do pai, vinculado ao peso do sobrenome. Obrist conduz o relato destacando o encontro de Anne com Duchamp, em 1967, na Filadélfia, e a morte dele, em 1968, no mesmo ano em que morre seu pai, René, além do contato dela com o curador Walter Hopps na escrita do ensaio sobre o Étant Donnés, obra que desencadeou seu interesse pelo artista.

A entrevista de Lucy Lippard (1937) foi realizada por telefone, em 2007, e ela lembra o início da sua carreira, no final dos anos 1950, junto aos curadores do MoMA, e sua primeira curadoria, em 1966, Abstração excêntrica, que incluía obras de Eva Hesse, Bruce Nauman, Louise Bourgeois, entre outros. A exposição causou polêmica, pois, na época, um crítico de arte não fazia exposições. Após isso, houve uma fusão entre a curadoria e a crítica de arte. Lippard também destaca suas aprendizagens práticas na organização de exposições e as dificuldades iniciais em relação aos limites entre crítica e curadoria.

No conjunto das entrevistas, uma das questões que Obrist não deixa de trazer a cada um dos entrevistados é sobre quem influenciou suas trajetórias, e alguns deles destacam a figura do holandês Willem Sandberg, diretor do Stedelijk Museum, de Amsterdam, um exemplo impulsionador e modelo seguido.

Conforme Daniel Birnbaum, no posfácio,"este é um livro sobre os antecessores de Hans Ulrich Obrist, seus avós”,' já que Suzanne Pagé e Kasper König a quem Obrist atribui sua trajetória (seus “pais”), não se encontram no livro. Pagé concede entrevista a Birnbaum dando a devida importância a Obrist: "Este livro é uma caixa de ferramentas única, e Hans Ulrich Obrist não é simplesmente um arqueólogo: ele também é um guia das paisagens artísticas que ainda estão por vir". ${ }^{3}$

Enfim, esta Breve história da curadoria conta uma parte significativa da vida de alguns de seus maiores curadores, as trajetórias pioneiras de uma profissão que foi inventada e que se reinventou nos diferentes lugares da arte, dos museus às galerias, e confere autoridade àqueles que abriram os territórios da arte e nos deixam um pouco do que é o ofício de curador.

\section{REFERÊNCIA}

OBRIST, Hans Ulrich. Uma breve história da curadoria. Tradução de Ana Resende. São Paulo: BEI Comunicação, 2010.

「」

2 OBRIST, 2010, p. 29I.

3 Ibidem, p. 296.

\section{SILVANA BOONE}

Professora do Centro de Artes e Arquitetura da Universidade de Caxias do Sul; mestre em Comunicação e Semiótica pela PUC-SP e doutoranda no PPG em Artes Visuais do Instituto de Artes da UFRGS.

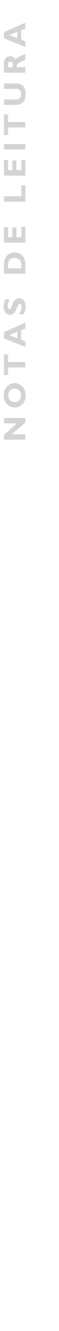

